\title{
Nasal Cavity and Ethmoid Sinus Cancer Clinical TNM Finding v7
}

National Cancer Institute

\section{Source}

National Cancer Institute. Nasal Cavity and Ethmoid Sinus Cancer Clinical TNM Finding v7. NCI Thesaurus. Code C89113.

A clinical finding about one or more characteristics of nasal cavity and ethmoid sinus cancer, following the rules of the TNM AJCC V7 classification system. The assessment is based on inspection and palpation, including examination of the orbits, nasal and oral cavities, and nasopharynx, and neurologic examination of the cranial nerves. Nasal endoscopy with rigid or fiberoptic flexible instruments is recommended. Radiologic assessment with magnetic resonance imaging (MRI) or computed tomography (CT) is mandatory for accurate pretreatment staging of malignant tumors of the sinuses. (from AJCC 7th Ed.) 